\title{
Anti-obesity and Anti-lipidemic Properties of Ascorbic Acid in Fructose Induced Obese Wistar Rats
}

\author{
Dr Temitope Deborah Fabiyi-Edebor
}

\section{ABSTRACT}

\begin{abstract}
There are controversies as to whether ascorbic acid is efficacious in inducing weight loss and lowering lipid in obese subjects. Therefore, this study investigates the role of ascorbic acid in the treatment of obesity. Twenty-four male wistar rats were randomly divided into control, fructose, ascorbic acid and statin $(n=6)$. Obesity was induced in the rats via free gavage drinking of fructose solution $(20 \% \mathrm{w} / \mathrm{v})$. Then, ascorbic acid group received $1 \mathrm{~g} / \mathrm{kg} / \mathrm{p} .0$ ascorbic acid while statin group received $200 \mathrm{mg} / \mathrm{kg} / \mathrm{p} . \mathrm{o}$ atorvastatin through oral canula for two weeks. The waist circumference, body weight, nose-anal length and Lee obesity index of the rats were measured using a vernier caliper, weighing balance and tape respectively. Serum Apolipoprotein A1 and B, Superoxide dismutase (SOD), malondialdehyde (MDA), glutathione (GSH) and ascorbic acid were determined spectrophotometrically. Analysis of variance (ANOVA) was used to analyze data at $\alpha=0.05$. The significant $(p<0.01)$ increases in waist circumference, body weight, nose-anal length, apolipoprotein $B$ and a lee index $>300$ indicated that fructose induced obesity and dyslipidemia in the wistar rats. But ascorbic acid and statin decreased $(\mathbf{p}<0.05)$ the waist circumference, body weight, Lee index and apolipoprotein $B$ in the obese rats. Also, serum MDA and SOD increased while glutathione and ascorbic acid decreased significantly $(p<0.05)$ in the obese rats, however, these were reversed upon ascorbic acid and statin treatment. Thus, ascorbic acid may serve as an anti-obesity and anti-lipidemic agent via acting on oxidative stress pathway.
\end{abstract}

Published Online: October 27, 2020

ISSN: 2593-8339

DOI: $10.24018 /$ ejmed.2020.2.5.527

\section{T. D. Fabiyi-Edebor}

Department of Physiology, College of Medicine and Health Sciences, Afe Babalola University, Ado-Ekiti, Ekiti, Nigeria.

(em-ail: $\quad$ fabiyitd@abuad.edu.ng; debbyteefab@gmail.com)

Keywords: Anti-oxidant, Ascorbic acid [vitamin C], Fructose, Obesity, Oxidative stress.

\section{INTRODUCTION}

Highlight Obesity is a clinical condition characterized by excess accumulated body fat detrimental to health. It is usually indicated by a body mass index [BMI] greater than $30 \mathrm{~kg} / \mathrm{m} 2$ and waist-hip ratio greater than $0.85 / 0.95$ in females/males. Obesity is a leading preventable cause of death globally with over 700 million adults and children having the condition as at 2015 amounting to about $12 \%$ of the world's population [1], [2]. It is a condition of public health concern as it is associated with morbidities such as cardiovascular diseases, type 2 diabetes, obstructive sleep apnea, osteoarthritis, depression and cancer [3], [4]. Consumption of fructose sweetened drinks is a contributing factor to the rising rates of obesity as it increases de novo lipogenesis and triglyceride accumulation [in adipocytes] which in excess results in oxidative stress [5], [6]. In obesity, adipocytes secrete bioactive molecules such as adipokine, cytokines and reactive oxygen and nitrogen species [6], [7]. Thus, the increased production of reactive species coupled with reduced anti-oxidant factors result in oxidative stress. Oxidative stress has been suggested as the link between obesity and its associated complications [6], [7], however, it has also been implicated in the pathogenesis of obesity as per it has been shown that oxidative stress leads to weight gain [6]. Hence, the use of potential pharmacological and nonpharmacological interventions aimed at reducing oxidative stress in obese individuals in order to reverse the condition and/or prevent the development of obesity-related complications. Such interventions serve as alternative therapies to anti-obesity drugs which usually have psychiatric, gastrointestinal and cardiovascular side effects [8].

Anti-oxidants are gaining more recognition in the management of obesity. Ascorbic acid is an anti-oxidant that has been reported to possess free radical scavenging potential.9 Studies have shown that obese individuals have ascorbic acid deficiency which strongly correlated positively with abdominal obesity, body fat, waist circumference and waist-hip ratio [10]-[12]. Thus, ascorbic acid may be beneficial in the treatment of obesity. However, more experimental studies are required to establish the use of ascorbic acid in obesity treatment because controversy abounds as to whether ascorbic acid is efficacious or not in 
inducing weight loss and lowering lipid in obese subjects [13]-[15]. Therefore, this study investigates the role of ascorbic acid in the treatment of obesity. The study hypothesizes that acute administration of ascorbic acid may reverse high calorie induced obesity by investigating the effects of ascorbic acid on parameters of obesity and lipidaemia in fructose induced obese wistar rats in comparison with statin.

\section{MATERIALS AND METHODOLOGY}

\section{A. Animal Grouping}

Twenty-four male Wistar rats weighting between 200$220 \mathrm{~g}$ were used for this study. They were bred and housed in a standard animal house where they were well cared for and had free access to standard pellet and clean drinking water. The rats were divided into four groups namely control, fructose, ascorbic acid and statin with $n=6$. Obesity was induced in the rats by giving them twenty percent fructose solution via free gavage drinking for two weeks while the control group kept drinking clean water. After the fructose feeding period, ascorbic acid group was treated with $1 \mathrm{~g} / \mathrm{kg} / \mathrm{p}$.o ascorbic acid (sigma) while the statin group received $200 \mathrm{mg} / \mathrm{kg} / \mathrm{p}$.o of statin [atorvastatin] through oral canula for two weeks.

\section{B. Waist circumference and Lee index of obesity}

The circumference of the rats was measured using a vernier caliper. Rats were restrained and the caliper was placed just before the hind limbs for this measurement.

\section{Body weight}

Rat bod weight was measured using a weighing balance while their nose-anal length (NAL) was measured using a standard measuring tape. The values of both weight and length were used to compute the lee index of obesity using the formula:

$$
\frac{(\mathrm{g})^{1 / 3} \times 1000}{\text { NAL[cm] }}
$$

\section{Lipid}

Lipid profile was assessed by examining the apolipoprotein B and A1 content of blood serum of the rats. Apolipoprotein A1 and B concentrations in the sera were measured spectrophotometrically using immunoturbidimetric assay.

\section{E. Oxidative stress}

Superoxide dismutase (SOD), malondialdehyde (MDA), glutathione (GSH) and ascorbic acid were measured using spectrophotometry.

\section{F. Statistical Analysis}

Results are presented as mean \pm S.E.M. and data was analyzed with ANOVA at $\mathrm{P}<0.05$.

\section{RESULTS}

The significant increase in body weight ( $\mathrm{p}<0.001$, Fig. 1), nose-anal length (Table 1), waist circumference ( $p<0.01$, Fig. $2)$, apolipoprotein B ( $>>0.05$, Table 2$)$ and a lee index greater than $300[p<0.01$, Fig. 3] indicated that fructose enriched drink induced obesity in the wistar rats. However, there was a significant decrease in the body weight (Fig. 1), waist circumference (Fig. 2) and Lee index (Fig. 3) of ascorbic acid and statin treated obese wistar rats, with the decrease in the ascorbic acid treated group more pronounced than in the statin treated group. Serum MDA and SOD increased whereas glutathione and ascorbic acid decreased significantly $(p<0.05)$ in the obese rats. However, these were reversed upon ascorbic acid and statin treatment (Table 2). Apolipoprotein A1 was significantly $(\mathrm{p}<0.05)$ decreased in fructose obese rats while apolipoprotein B was decreased $(\mathrm{p}<0.05)$ in ascorbic acid and statin groups (Table 3$)$.

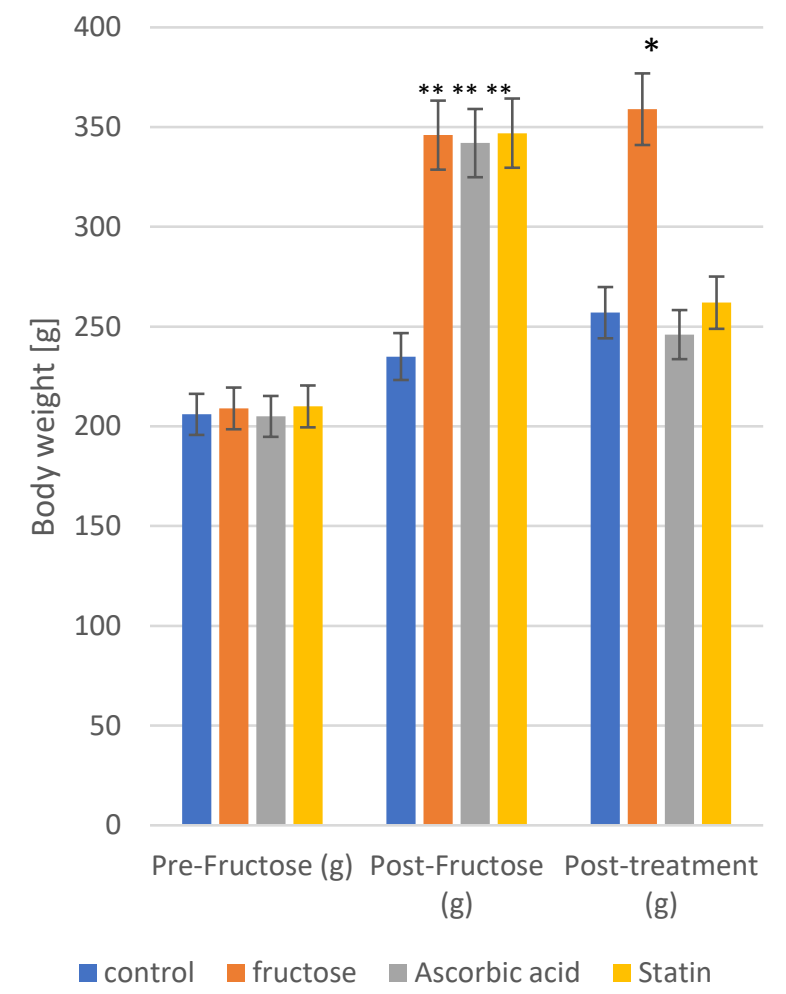

Fig. 1. Effect of ascorbic acid and statin on fructose induced weight gain in wistar rats. Results $=$ mean + SEM, ${ }^{*} p<0.05, * *_{p}<0.01, p<0.001$.

TABLE 1: EFFECT OF ASCORBIC ACID AND STATIN ON THE NOSE-ANAL LENGTH OF FRUCTOSE INDUCED OBESE RATS

\begin{tabular}{cccc}
\hline Groups & $\begin{array}{c}\text { Pre-Fructose } \\
{[\mathrm{cm}]}\end{array}$ & $\begin{array}{c}\text { Post-Fructose } \\
{[\mathrm{cm}]}\end{array}$ & Post-treatment $[\mathrm{cm}]$ \\
\hline control & $\mathbf{2 2 . 6} \pm \mathbf{1 . 0}$ & $\mathbf{2 3 . 2} \pm \mathbf{2}$ & $\mathbf{2 3 . 7} \pm \mathbf{1 . 8}$ \\
fructose & $\mathbf{2 2 . 5} \pm \mathbf{1 . 7}$ & $\mathbf{2 3} \pm \mathbf{2}$ & $\mathbf{2 3 . 2} \pm \mathbf{2 . 2}$ \\
Ascorbic & $\mathbf{2 2 . 4} \pm \mathbf{0 . 5}$ & $\mathbf{2 2 . 8} \pm \mathbf{1}$ & $\mathbf{2 3 . 9} \pm \mathbf{1}$ \\
acid & $\mathbf{2 2 . 6} \pm \mathbf{1}$ & $\mathbf{2 3} \pm \mathbf{1 . 5}$ & $\mathbf{2 4} \pm \mathbf{1 . 5}$ \\
Statin & &
\end{tabular}

Results $=$ mean \pm S.E.M. ${ }^{*} \mathrm{p}<0.05$. ap $>0.05$. 


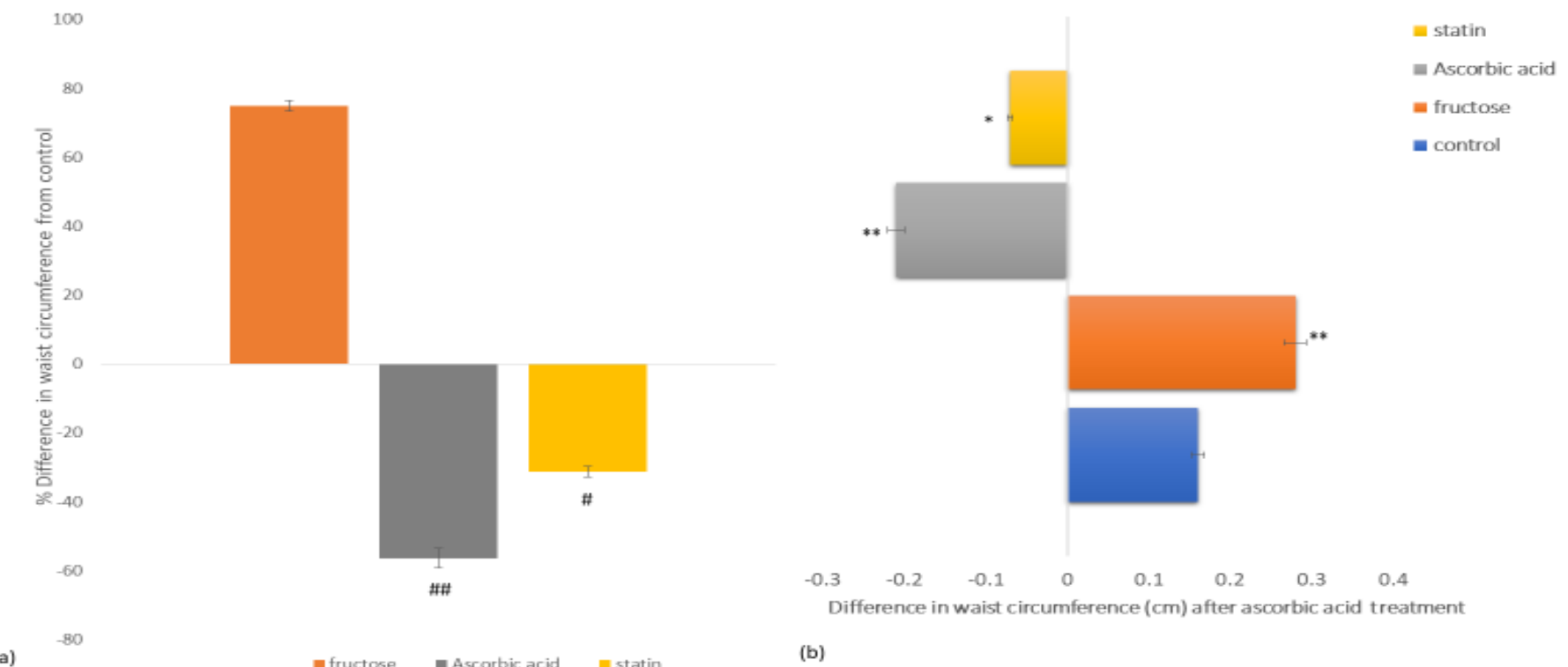

Fig. 2. (a) The percentage difference in waist circumference. (b) Waist circumference of fructose obese rats after ascorbic acid and statin treatments. $* * p<0.01$

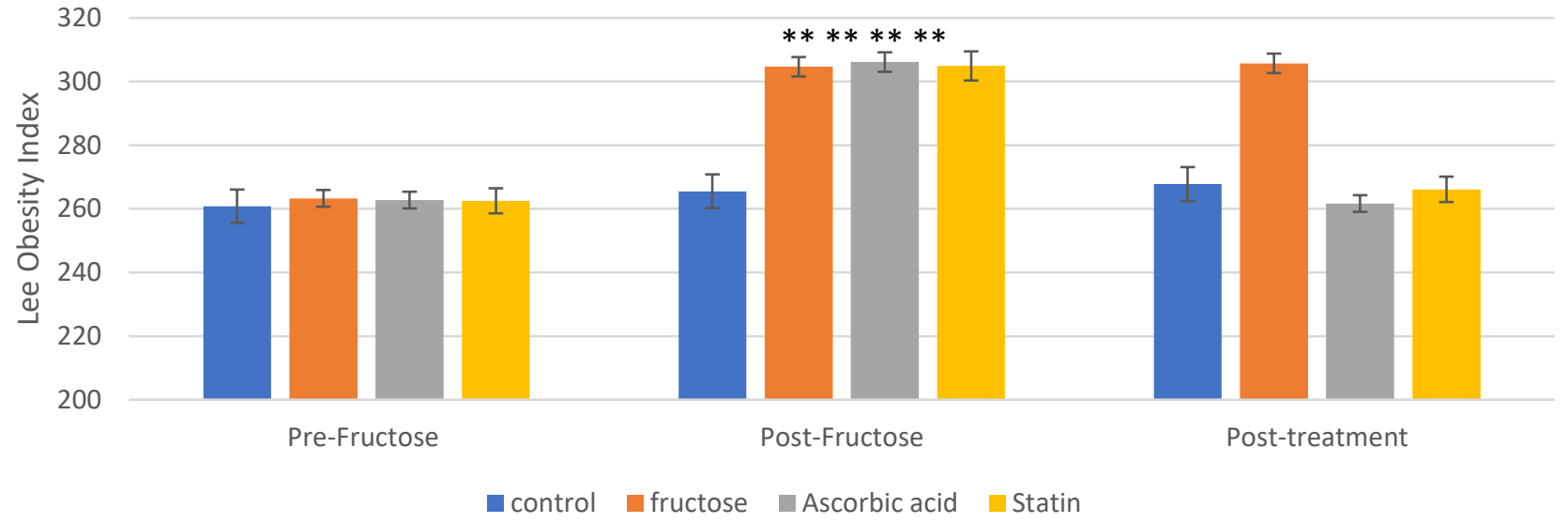

Fig. 3. Ascorbic acid and Statin effect on the Lee Obesity index of Fructose Obese Wistar rats. **p $<0.01$.

TABLE 2: OXIDATIVE STRESS MARKERS IN FRUCTOSE INDUCE OBESE RATS TREATED WITH ASCORBIC ACID AND STATIN

\begin{tabular}{ccccc}
\hline $\begin{array}{c}\text { Oxidative stress } \\
\text { markers }\end{array}$ & Control & Fructose & $\begin{array}{c}\text { Ascorbic } \\
\text { acid }\end{array}$ & Statin \\
\hline $\begin{array}{c}\text { SOD [unit } \\
\text { SOD/min] }\end{array}$ & $0.7 \pm 0.1$ & $1.4 \pm 0.2^{* *}$ & $0.6 \pm 0.1^{\#}$ & $0.74 \pm 0.1^{\#}$ \\
MDA & & & & \\
[nmol/mgprotein] & $9.3 \pm 1$ & $16.4 \pm 2^{* *}$ & $8.0 \pm 1^{\#}$ & $8.9 \pm 1^{\#}$ \\
GSH [mg/dl] & $11.8 \pm 2$ & $5.3 \pm 1^{* *}$ & $12.3 \pm 2^{\#}$ & $11.2 \pm 2^{\#}$ \\
AA [ $\mu \mathrm{gg} / \mathrm{ml}]$ & $61 \pm 5$ & $39.2 \pm 2^{* *}$ & $62.3 \pm 6^{\#}$ & $62.3 \pm 8^{\#}$ \\
\hline$* * * \mathrm{p}<0.001, * \mathrm{p}<0.05$. & & &
\end{tabular}

TABLE 3: THE ANTI-LIPIDEMIC EFFECT OF ASCORBIC ACID AND STATIN ON FRUCTOSE FED OBESE WISTAR RATS

\begin{tabular}{ccccc}
\hline & Control & Fructose & Statin & Ascorbic acid \\
\hline APO-B [mg/dl] & $36.4 \pm 4$ & $48.6 \pm 7^{*}$ & $37.6 \pm 5^{\#}$ & $34.2 \pm 5^{\#}$ \\
APO-A1 [mg/dl] & $60.8 \pm 2$ & $51.6 \pm 3^{*}$ & $64.3 \pm 3^{\#}$ & $71.9 \pm 5^{*}$
\end{tabular}

Results $=$ mean \pm S.E.M; $* p<0.05,{ }^{*} p>0.05$.

Apo $=$ Apolipoprotein.

\section{DISCUSSION}

Obesity was induced in the rats after drinking twenty percent fructose solution, in addition to their normal chow diet, freely for two weeks. This is shown by the increased body weight, waist circumference and a 'Lee index of obesity' greater than 300 [16], [17]. A Lee obesity index greater than 300 is widely accepted as an indicator for the presence of obesity in rats [17], [18]. The Lee obesity index is the equivalent of BMI used to depict obesity in humans. It correlated positively with percentage body fat and weight for animals made obese by diet and is thus a simple and reliable predictor for percentage body fat and obesity in rodents [18]. In this study, obese rats treated with ascorbic acid showed marked weight loss and a reduction in Lee obesity index to a non-obese value similar to control and statin treated groups. This indicated that ascorbic acid was effective in reducing percentage body fat and waist fat in addition to causing weight loss. Diet induced obesity may be associated with oxidative stress [19]-[21] as shown in this study by the increased super oxide activities and malondialdehyde 
production from peroxidation of lipids. In addition, lipid peroxidation is an oxidative marker which correlates positively with lee obesity index and waist circumference [17]. Thus, ascorbic acid may exert its anti-obesity effects by acting on the oxidative stress pathway via eliminating reactive oxygen species such as super oxide, downregulating lipid peroxidation (MDA) and increasing endogenous glutathione antioxidant levels. Another possible mechanism by which ascorbic acid may induce weight loss in obesity may be by interfering with the leptin pathway as ascorbic acid has been reported to inhibit leptin secretion which may in turn alter eating habits to reduce food intake and promote the feeling of satiety [19], [20]. In this study, ascorbic acid ameliorated dyslipidemia in the obese rats by downregulating apolipoprotein B, a low-density lipoprotein (LDL) indicator, and upregulating apolipoprotein A1, a high-density lipoprotein (HDL) predictor. This effect was also observed in obese rats treated with statin a reductase inhibitor used in lowering LDL cholesterol. Statin has been shown to have antioxidant properties in addition to its anti-lipidemic effect, however, ascorbic acid is a more potent anti-oxidant. Increased apolipoprotein B and decreased apolipoprotein A are reliable indicators of the presence of dyslipidemia. Dyslipidemia is a complication of obesity that has been linked, to a large extent, to increased oxidative stress ${ }^{21}$. Thus, ascorbic acid may ameliorate dyslipidemia by interfering with the oxidative stress pathway involved in its pathogenesis.

\section{CONCLUSION}

Ascorbic acid may serve as an adjunct therapy in the treatment of obesity and dyslipidemia via acting on oxidative stress pathway to decrease the production of reactive molecules and increase endogenous anti-oxidant statin.

\section{APPENDIX}

Conflict of interest: The author declares no conflict of interest

Ethical approval: Experiments were carried out as approved by ABUAD animal research committee.

\section{ACKNOWLEDGMENT}

The author would like to thank Dr Solomon Edebor for editing this article.

\section{REFERENCES}

[1] World Health Organisation. "Obesity and overweight Fact sheet No311". W.H.O. 2015.

[2] Afshin A, Forouzanfar MH, Reitsma MB, Sur P, Estep K, Lee A, Marczak L, Mokdad AH, Moradi-Lakeh et al. "Health Effects of Overweight and Obesity in 195 Countries over 25 Years". The New England Journal of Medicine. 377 [1]: 13-27. 2017.

[3] Haslam DW, James WP. "Obesity". Lancet [Review]. 366 [9492]:1197-209. 2005.

[4] Luppino FS, de Wit LM, Bouvy PF, Stijnen T, Cuijpers P, Penninx BW, Zitman FG. "Overweight, obesity, and depression: a systematic review and meta-analysis of longitudinal studies". Archives of General Psychiatry.67[3]: 220-9. 2010.
[5] Baena, M., Sangüesa, G., Dávalos, A. et al. Fructose, but not glucose, impairs insulin signaling in the three major insulin-sensitive tissues. Sci Rep 6, 26149. 2016.

[6] Savini I., Gasperi V., Catani M.V. [2016] Oxidative Stress and Obesity. In: Ahmad S., Imam S. [eds] Obesity. Springer, Cham.

[7] Engin A. 'The Pathogenesis of Obesity-Associated Adipose Tissue Inflammation. In: Engin A., Engin A. [eds] Obesity and Lipotoxicity. Advances in Experimental Medicine and Biology, 960. 2017.

[8] Dietrich, Marcelo \& Horvath, Tamas. Dietrich, MO and Horvath, TL. Limitations in anti-obesity drug development: the critical role of hunger-promoting neurons. Nat Rev Drug Discov 11: 675-691. 2012.

[9] Diego Fernando Garcia-Diaz, Patricia Lopez-Legarrea, Pablo Quintero, Jose Alfredo Martinez. Vitamin C in the Treatment and/or Prevention of Obesity [Review]. Journal of Nutritional Science and vitaminology. 60[6]:367-379. 2014.

[10] Singh, R.B., Beegom, R., Rastogi, S.S., Gaoli, Z., Shoumin, Z. Association of low plasma concentrations of antioxidant vitamins, magnesium and zinc with high body fat per cent measured by bioelectrical impedance analysis in Indian men. Magnesium Research. 11[1]:3-10. 1998.

[11] Canoy, D., Wareham, N., Welch, A., Bingham, S., Luben, R., Day, N., and Khaw. K.T. Plasma ascorbic acid concentrations and fat distribution in 19,068 British men and women in the European prospective investigation into cancer and nutrition Norfolk cohort study. Am J Clin Nutr. 82[6]:1203-1209. 2005.

[12] Aasheim, E.T., Hofso, D., Hjelmesaeth, J., Birkeland, K.I., and Bohmer. T. Vitamin status in morbidly obese patients: a cross sectional study. Am J Clin Nutr. 87[2]:362-369. 2008.

[13] Abdel-Wahab YH, O'Harte FP, Mooney MH, Barnett CR, Flatt PR Vitamin $\mathrm{C}$ supplementation decreases insulin glycation and improves glucose homeostasis in obese hyperglycemic [ob/ob] mice. Metabolism 51:514-517. 2002.

[14] Buşra Totan, Hatice Baygut, Makbule Gezmen Karadag. [2019]. Vitamin C Physiology: The Known and the Unknown in Obesity. Journal of Food and Nutrition Research, 7[8]: 613-618. 2019.

[15] Rosita V. Sandeva, Stanislava M. Mihaylova, Katya Y. Trifonova, Ruska D. Popova-Katsarova. Effect of high fructose solution on body weight, body fat, blood glucose and triglyceride levels in rats. J. Biomed Clin Res, 8[1]:5-8. 2015.

[16] Debora C. Damasceno Yuri K. Sinzato Aline Bueno Bruna Dallaqua Paula H. Lima Iracema M.P. Calderon Marilza V.C. Rudge Kleber E. Campos. Metabolic profile and genotoxicity in obese rats exposed to cigarette smoke. Obesity, 21[8]:1596-1601. 2013.

[17] Simson EL, Gold RM. The Lee Obesity Index vindicated? Physiol Behav.;29[2]:371-6. 1982.

[18] MOLZ, Patrícia, RAEL, Alana Nunes, FISCHER, Maiara de Queiroz, LIMBERGER, Luana Beatriz, PRÁ, Daniel, \& FRANKE, Silvia Isabel Rech. Vitamin C decreases the obesogenic and hyperglycemic effect of invert sugar in prediabetic rats. Revista de Nutrição, 30[1], 23-32. 2017.

[19] Garcia-Diaz DF, Campion J, Milagro FI, Boque N, Moreno-Aliaga MJ, Martinez JA. Vitamin C inhibits leptin secretion and some glucose/lipid metabolic pathways in primary rat adipocytes. J Mol Endocrinol.;45[1]:33-43. 2010.

[20] Carillon J, Romain C, Bardy G, Fouret G, Feillet-Coudray C, Gaillet S, et al. Cafeteria diet induces obesity and insulin resistance associated with oxidative stress but not with inflammation: Improvement by dietary supplementation with a melon superoxide dismutase. Free Radic Biol Med; 65:254-61. 2013.

[21] Priya Nijhawana, Sandeep Arorab, Tapan Behl. Intricate role of oxidative stress in the progression of obesity. Obesity Medicine. 15:100125. 2015. 